\title{
The Portrayal of Paralysis in some Masterpieces by European Painters
}

\author{
K. Ohry-Kossoy, MA, A. Ohry MD \\ Neurological Rehabilitation Department, Sheba Medical Center, Tel-Hashomer 52621, \\ Israel
}

Key words: Paralysis; Art; History

It is widely known that the survival rate of spinal injury victims was very low until the middle of the twentieth century. Those spinal patients who did survive in earlier times had low or incomplete lesions mainly caused by syphilis, spina bifida, leprosy, tuberculosis of the spine or other infectious diseases, and hysteria. There is little written documentation about these cases over the past centuries, but they are sometimes portrayed in works of art, some of them by famous painters. By observing these figures we can achieve a better understanding of the pictures they appear in, and obtain valuable information on the fate of the paralysed in the distant past.

We discuss a small selection of works of art, all of them by great European masters, and all of them showing disabled figures in a particularly clear manner. The earliest are from the fifteenth and the latest from the eighteenth century.

The first painting is at the Santa Maria del Carmine in Florence, a fresco from about 1427 by Masaccio: St Peter healing the Sick with his Shadow while going to the Temple with St Fohn. St Peter is a stern, stately figure who passes by the sick men, neither touching them, nor even looking at them, healing them through the mere projection of his shadow (Clark, 1969). The crouching figure at the feet of the saint is a lame young man, probably paralysed, seated on a mat or some other support. Both his legs are thin, contracted, and bare. His elbows rest on two small wooden crutches with which he pushes himself forward. His well developed arms indicate that he makes much use of this form of locomotion. All the people represented in Masacio's fresco are realistic figures, each carefully depicted. Yet a social hierarchy is evident from their respective positions: a monumental St Peter is at the center, and those standing around him come next. Then the observer's eye travels downward to the sick men, finally resting on the paralytic figure, whose head reaches the height of the saint's knee. Still, although the disabled man is at the lowest point in the painting, he is not grotesque, and has his share of the human dignity that Masaccio highlighted in his art.

About 20 years later, Fra Angelico painted a somewhat similar scene for the Chapel of Nicholas V in the Vatican: St Lawrence distributing the Treasures of the 


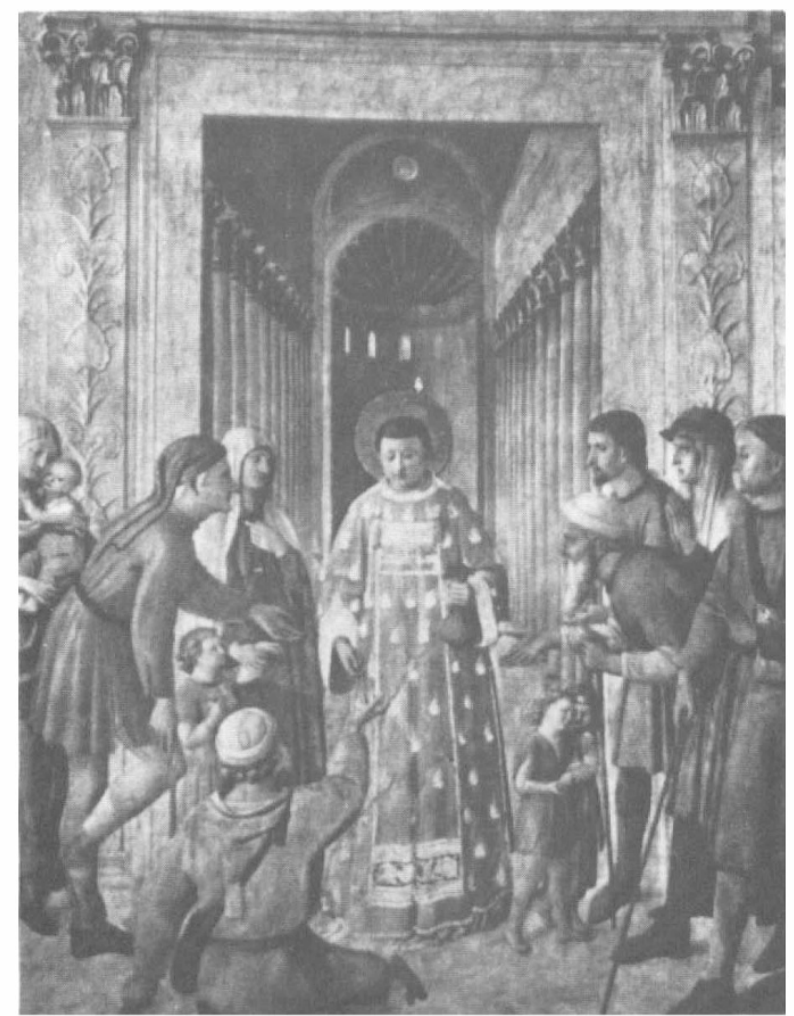

Figure 1 Fra Angelico, St Lawrence distributing the Treasures of the Church (1447/1450). Chapel of Nicholas V, Vatican. Reprinted with permission.

Church (Fig. 1). At least 4 of the people surrounding the saint are disabled. The one we are particularly interested in sits in the foreground with his back to us, facing the saint. His back is straight, his arms very strong. As in Masaccio's fresco, he is seated on some kind of mat, uses small wooden crutches, and is probably paralysed. He too appears at the bottom of the scene. But he will be the first in the group to receive a gift of money from St Lawrence, and his extended hand has caught the saint's gaze. Here, even more than in Masaccio's painting, the disabled do not differ in dress or appearance from the able-bodied figures. They are all part of one human group contrasted with the saint's richly adorned, otherworldly apparition.

A little later, in the Netherlands, Hieronymus Bosch (1450-1516) presented no less than 31 disabled beggars in his drawing Cripples and Beggars (Fig. 2), about which Dequeker (1979) writes: 'we see a number of figures drawn from reality for whom a differential diagnosis is inescapable between bone tuberculosis, polyarthritis, osteomyelitis, lues, leprosy, neurological disorders and war wounds (Vogt). Undoubtedly, there are cases of leprosy among them in view of the fact that they also carry the clapper and the wooden bowl which leprosy patients always had to carry with them as an indication of their condition. It is striking to note the number of people with stiffening of the knee joints, sometimes in combination with abnormalities of the foot. 


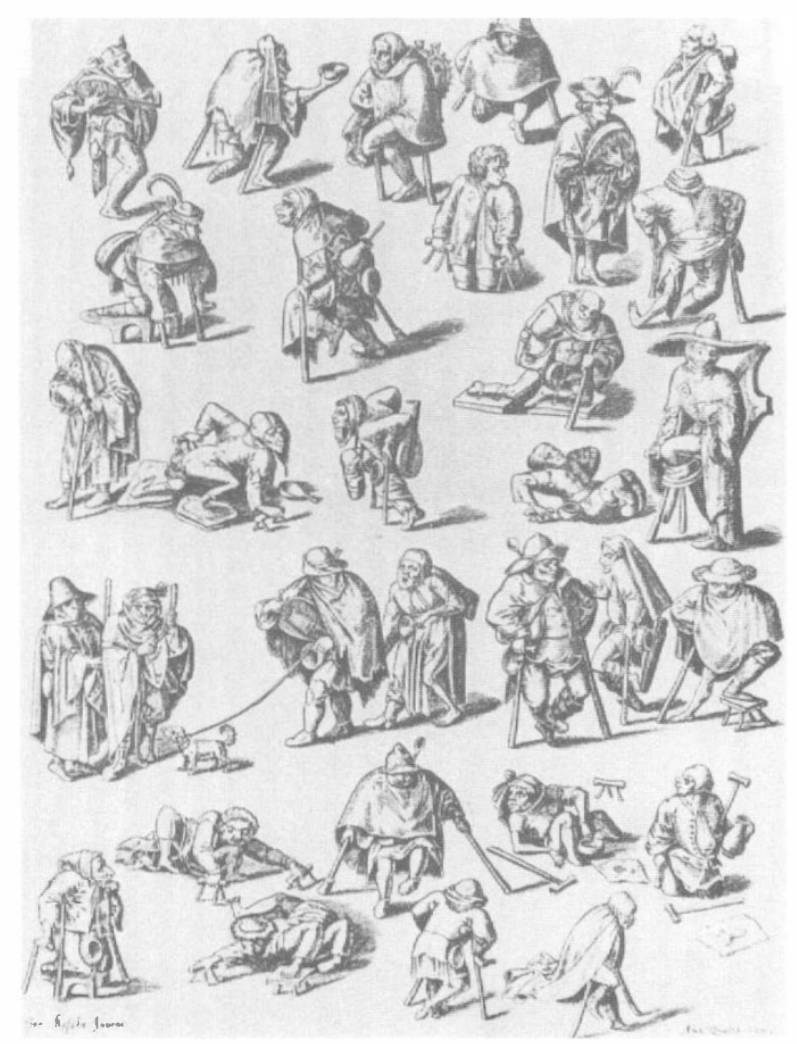

Figure 2 Bosch, Cripples and Beggars (no date). Graphische Sammlung Albertina, Vienna. Reprinted with permission.

We see people with bilateral knee abnormalities, with genu recurvatum, muscular atrophy, and complete paralysis. Some of these abnormalities, however, could also be attributable to an ergotamine intoxication (St Anthony's fire) since at that period ergot frequently occurred as a weed amongst the grain.

Most of these 31 figures are amputees or suffer from severe malformations. Only 6 of them use the small hand crutches we have seen before, and are probably paralysed.

A true son of his time, Bosch was a deeply religious artist who stressed the dark pessimistic side of faith. To him man is essentially corrupt, and will be punished for his sins both during his life and after his death (Foote, 1968). His crippled beggars are depicted with sharp realism but also with a streak of satire which prevents pity or empathy.

The next painting, painted in about 1516, is again from Italy and has much in common with those by Masaccio and Fra Angelico: The Healing of the Lame Man at the Beautiful Gate of the Temple by Raphael (Fig. 3). The two Apostles in it are very handsome, the lame man's face and foot are distorted, and it seems his back is humped. He holds a crutch in his hand and could be a poliomyelitis victim. Shirley (1977) writes about this painting, one of Raphael's famous Cartoons: 'the theme of the Healing at the Golden Gate implied a kind of liberation; and the bizarre, twisted columns, which were believed to have come from the Temple at 


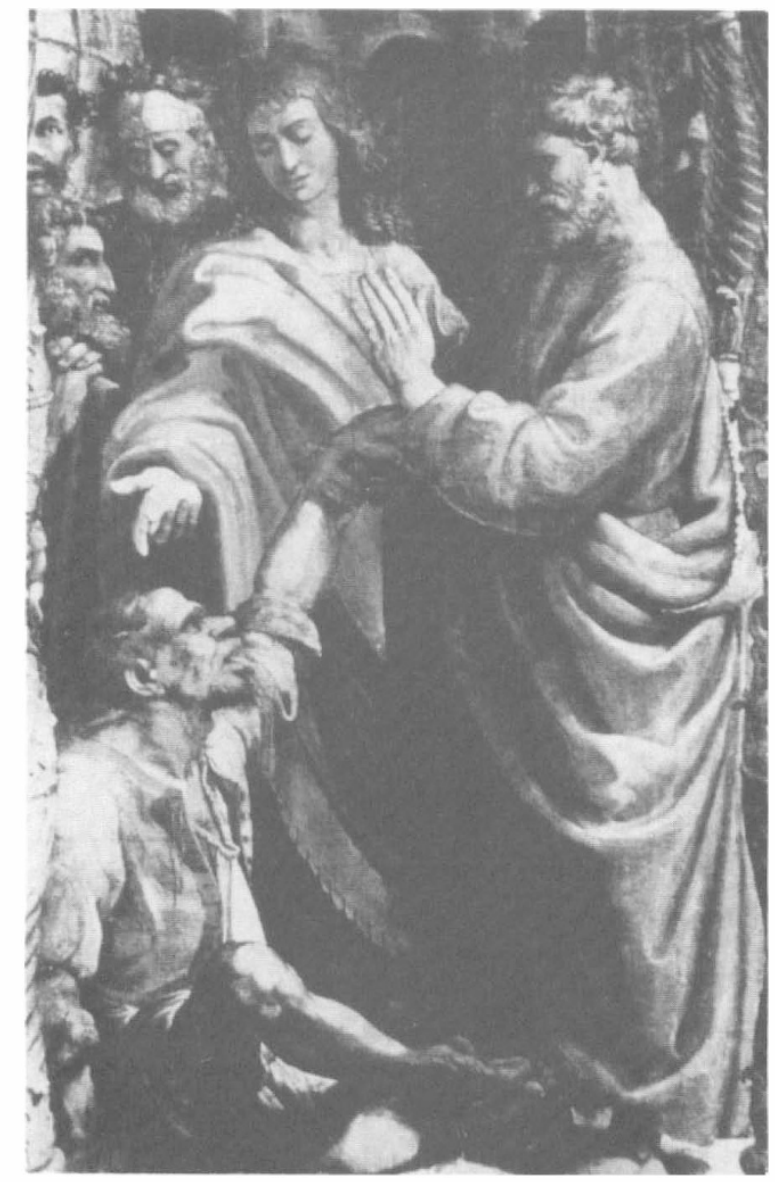

Figure 3 Raphael, The Healing of the Lame Man at the Beautiful Gate of the Temple (c. 1516). Victoria and Albert Museum, London. Reprinted with permission.

Jerusalem, contribute decisively to the effect. The two Apostles and the cripple are squeezed in between, they are confined just as the cripple's joints have been imprisoned by pain. As his body cracks awkwardly into new life, the force of the miracle bursts the bonds of the narrow space.'

As only Bosch had done before him, Bruegel (1525-1569) sketched and painted an unusual number of disabled figures. Bruegel was strongly influenced by Bosch (Foote, 1968). Both artists, reflecting a reality that remained unchanged for centuries, mainly depict amputation and malformation while paralysed figures are much less frequent.

In a drawing from 1559, Caritas (Fig. 4), a paralysed beggar receives a loaf of bread. His terribly distorted legs rest on his humped back, he lies in a basket instead of a mat, and he has regular slippers on his hands instead of the usual hand crutches. That same year (1559), Bruegel painted a famous masterpiece of The Battle between Carnival and Lent (Fig. 5), in which there is an especially interesting group of crippled beggars. One of them is paralysed, and is very similar to the one in the Caritas drawing. Foote (1968) writes 'As a caricaturist Bruegel 


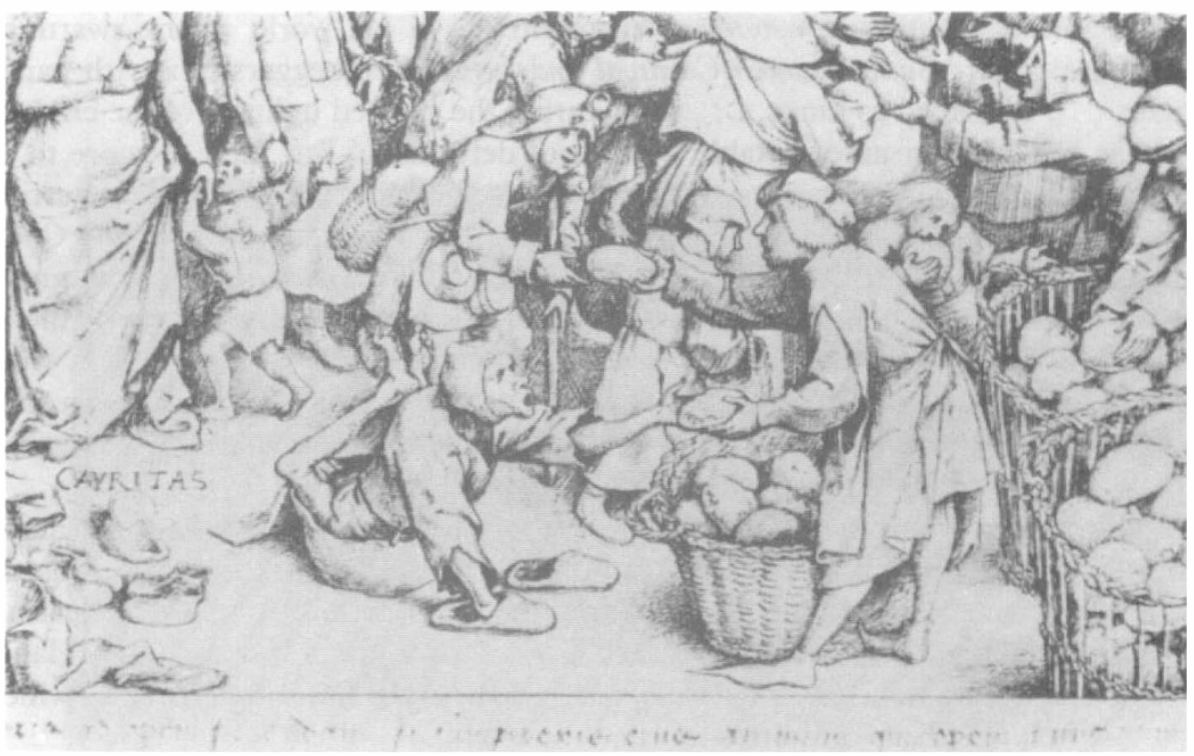

Figure 4 Bruegel, Caritas (1559). Museum Boymans-van Beuningen, Rotterdam. Reprinted with permission.

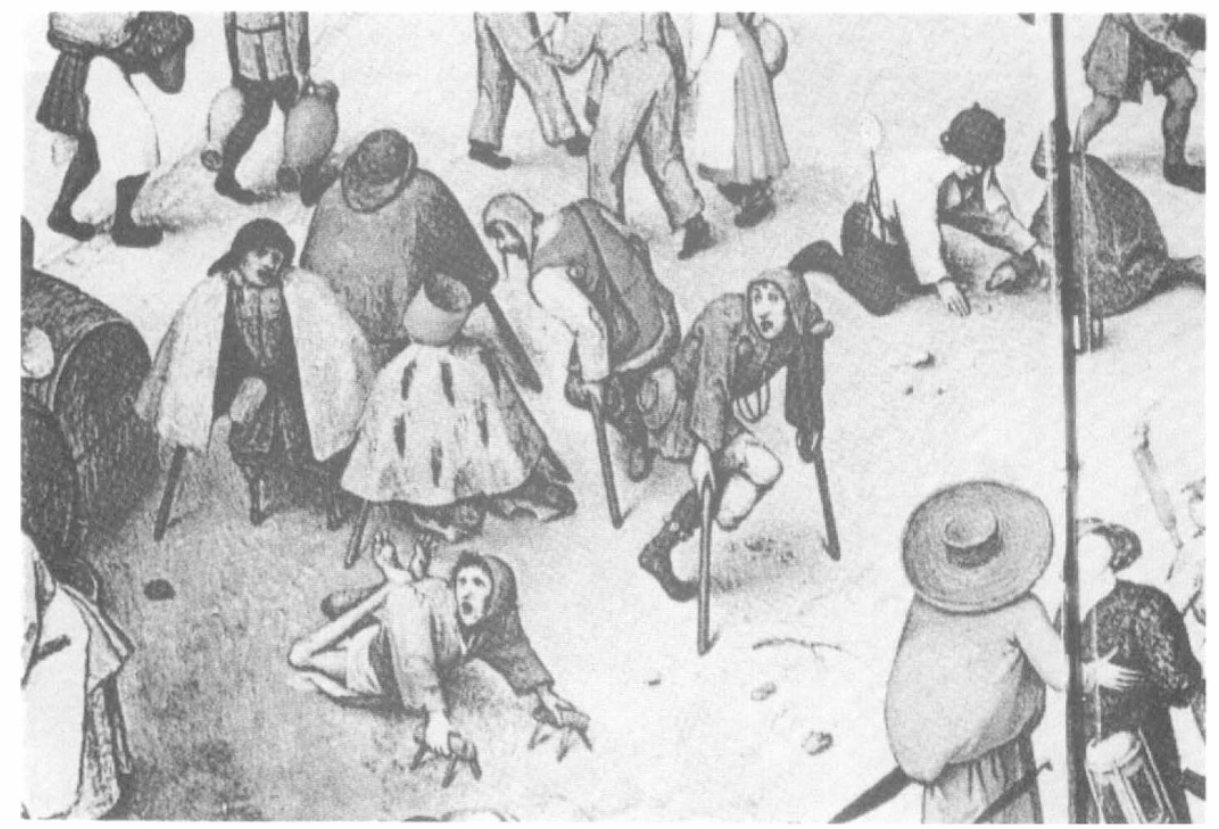

Figure 5 Bruegel, The Battle between Carnival and Lent (1559). Kunsthistorisches Museum, Vienna. Reprinted with permission. 
best summed up the persistently stark contrasts of his world in the swarming activities of The Battle between Carnival and Lent. Here beggars mix with partygoers . . . costumed as kings, . . . in picturing the gnarled ugliness of the cripples he has provided an unforgettable portrait of deformity.' But there is more to it: 'Bruegel's contemporaries . . . saw deformed bodies as cruel proof that an erring man was paying the wages of sin through loss of the symmetry ordained by God'. Last but not least, this painting may also have a political meaning. At the time it was created, a group of Flemish aristocrats who rebelled against Spanish rule in the Netherlands, took the name 'Beggars' and 'carried beggars' bowls, . . . wore chains and foxtail - the traditional beggar's emblem seen in the painting. In time ... the nobles rebellion erupted into a full-scale war for independence against Spain, and "Long live the Beggars" became a national rallying cry.'

Rembrandt (1606-1669) often showed sick, injured or disabled people in his works over the years, usually in illustrations of New Testament texts. These figures are not the main subjects of the pictures they appear in, and they lack visual details for a medically oriented analysis. We will therefore only cast a quick glance at one etching by Rembrandt St Peter and St Fohn at the Gate of the Temple, which presents yet another lame beggar.

Again, based on a text from the New Testament (St John), but much more explicit from our point of view is a painting by a Spanish contemporary of Rembrandt's Murillo (1617-1682): The Healing of the Paralytic at the Pool of

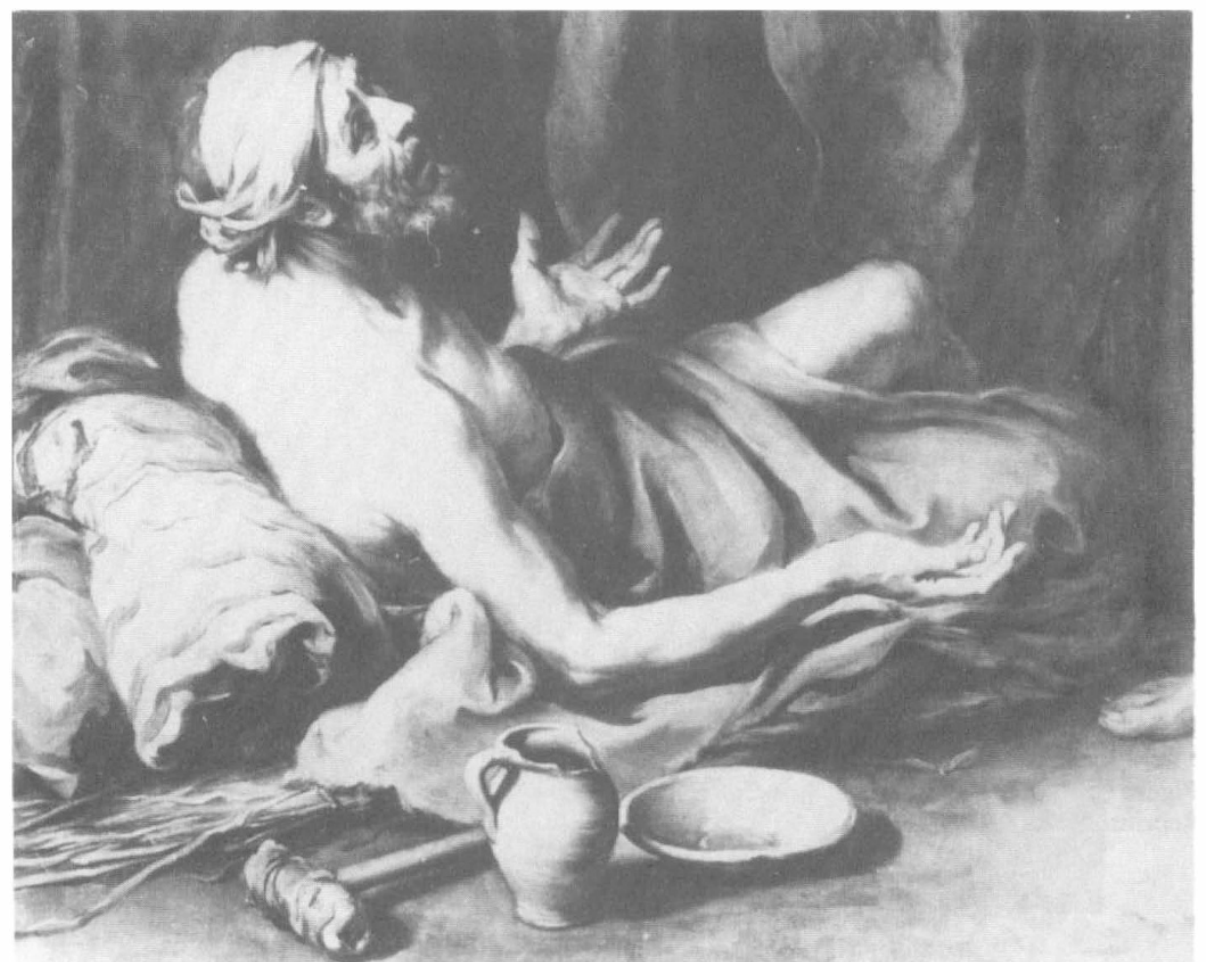

Figure 6 Murillo, The Healing of the Paralytic at the Pool of Bethesda (1668). National Gallery, London. Reprinted with permission from the Trustees of the British Museum. 


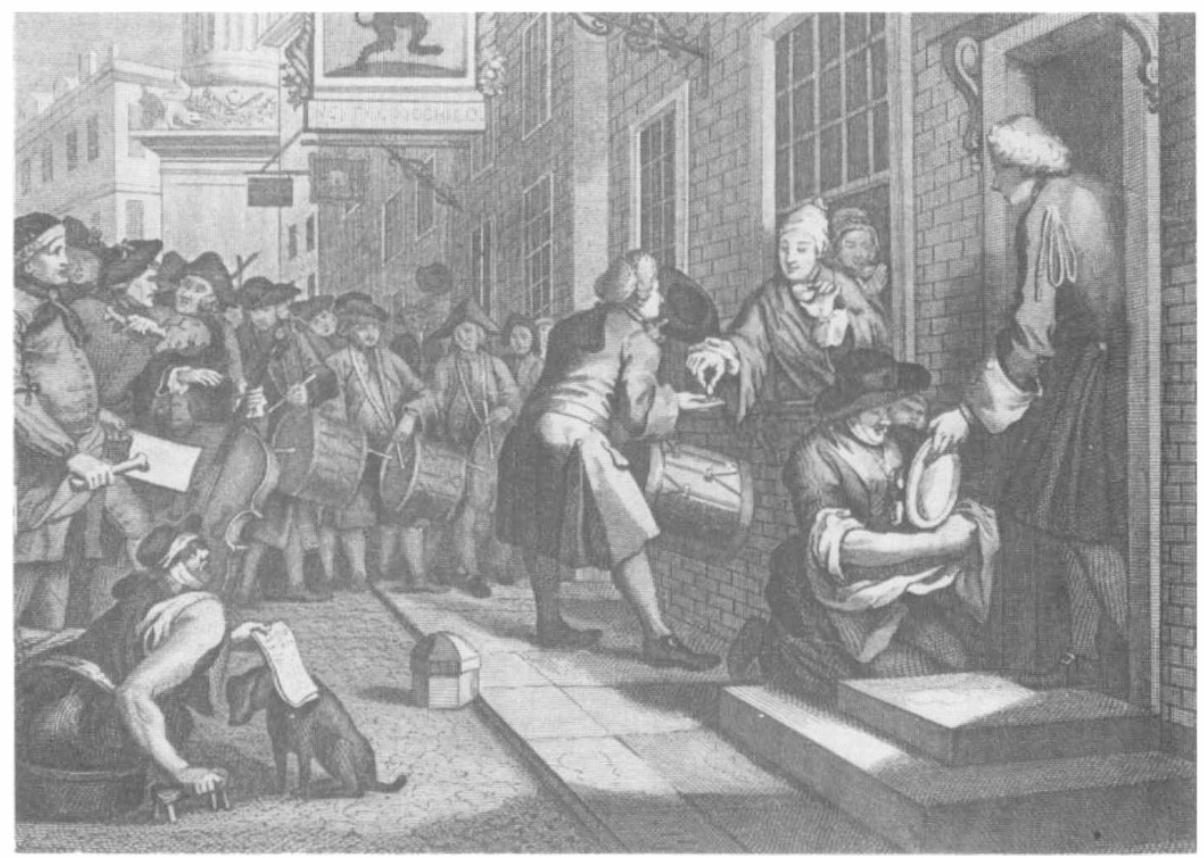

Figure 7 Hogarth, Industry and Idleness (series of prints), Plate 6, The Industrious Prentice out of his Time and Married to his Master's Daughter (1747). Reprinted with permission from the Trustees of the British Museum.

Bethesda (Fig. 6). A lame old man raises himself with a supplicating gesture towards Jesus. There is an axillar crutch near him. His torso and arms are well developed, possibly his legs too. The cause of paralysis is unclear, perhaps hysteria. According to the Bible, Jesus will make him walk again, which suggests that he was not fully paralysed.

The last picture is a print by William Hogarth (1697-1764) from the series Industry and Idleness published in 1747 (Fig. 7). The Rev. Dr Trusler (1841) writes: 'That cripple, on the left of this piece, was intended for a well known beggar, called Philip-in-the-tub (from his being reduced to the shift we see, in order to supply his unhappy want of limbs), who, in the principal towns of Ireland, and the Seven Provinces, as well as those of Great Britain, was a constant attendant at all weddings as an epithalamist' (composer of wedding songs). This particular poet's condition clearly demonstrates that 300 years after Masaccio's painting, the first in our series, nothing much had changed for paralysed patients. Another 200 years will have to pass before the advent of modern rehabilitation.

\section{References}

Clark K 1972 Civilisation-A Personal View. BBC and John Murray, London, p 92.

DEQUEKER J 1979 Rheumatism in the art of the late middle ages. Organorama 16:9-19.

FOOTE T 1971 The World of Bruegel c. 1525-1569. Time-Life Library of Art, New York.

ShIRLEY M 1978 Raphael. The Great Artists, a Library of their Lives, Times and Paintings, book 15. Funk Wangalls, New York.

TRUSLER 1841 Hogarth Moralized. H Washbourne, London. pp 89-91. 